Abstract G472 Table 1 Parents' explanations for the 10 most common symptoms

\begin{tabular}{|c|c|c|c|c|}
\hline Symptom & $n$ & $\begin{array}{c}\text { Numberwithexplanation for } \\
\text { symptom }\end{array}$ & $\begin{array}{r}\text { Most commone } \\
n(\%)\end{array}$ & nations \\
\hline Polydipsia & 85 & $58(68.2)$ & $\begin{array}{l}\text { Hotweather } \\
\text { Infection } \\
\text { Activity/Travel }\end{array}$ & $\begin{array}{l}19(32.8) \\
13(22.4) \\
10(17.2)\end{array}$ \\
\hline Polyuria & 73 & $47(64.4)$ & $\begin{array}{l}\text { Drinking more } \\
\text { Urine infection } \\
\text { Diabetes }\end{array}$ & $\begin{array}{c}29(61.7) \\
6(12.7) \\
4(8.5)\end{array}$ \\
\hline Tiredness & 66 & $44(66.7)$ & $\begin{array}{l}\text { School related } \\
\text { Infection } \\
\text { Nocturia }\end{array}$ & $\begin{array}{c}12(27.3) \\
5(11.9) \\
4(9.5)\end{array}$ \\
\hline Nocturia & 64 & $40(62.5)$ & $\begin{array}{l}\text { Drinking move } \\
\text { Diabetes } \\
\text { Urine infection }\end{array}$ & $\begin{array}{l}26(65.0) \\
4(10.0) \\
3(7.5)\end{array}$ \\
\hline Weight loss & 56 & $33(58.9)$ & $\begin{array}{l}\text { Growth related } \\
\text { Decreased appetite } \\
\text { Increased activity }\end{array}$ & $\begin{array}{l}15(45.5) \\
4(12.1) \\
3(9.1)\end{array}$ \\
\hline Changes in behaviaurimood & 48 & $31(64.6)$ & $\begin{array}{l}\text { Tiredness } \\
\text { Age relatedipuberty } \\
\text { Infectionillness }\end{array}$ & $\begin{array}{l}10(32.3) \\
7(22.6) \\
6(19.4)\end{array}$ \\
\hline Change in appetite & 45 & $28(62.2)$ & $\begin{array}{l}\text { Grow th related } \\
\text { Infection } \\
\text { Holiday related }\end{array}$ & $\begin{array}{l}14(50.0) \\
5(17.9) \\
2(7.1)\end{array}$ \\
\hline Abdominal pain & 37 & $19(51.4)$ & $\begin{array}{l}\text { Infection } \\
\text { School related } \\
\text { Period pains }\end{array}$ & $\begin{array}{l}4(21.1) \\
3(15.8) \\
3(15.8)\end{array}$ \\
\hline Noctumal erouresis & 33 & $23(69.7)$ & $\begin{array}{l}\text { Drinking more } \\
\text { Tired } \\
\text { School related }\end{array}$ & $\begin{array}{l}13(56.5) \\
4(17.4) \\
3(13.0)\end{array}$ \\
\hline Differents melling breath & 31 & $14(45.2)$ & $\begin{array}{l}\text { Poor dental hygiene } \\
\text { Infection } \\
\text { Diabetes }\end{array}$ & $\begin{array}{l}4(28.6) \\
3(21.4) \\
3(21.4)\end{array}$ \\
\hline
\end{tabular}

diagnosis. Responses were grouped into similar categories and coded.

Results 88/164 (54\%) of invited families returned the questionnaire. The time from symptom onset to diagnosis ranged from 2 to 315 days (median 25 days). Most of this was the appraisal interval from symptom onset until perceiving the need to seek medical advice (median 25 days (interquartile range 14-50)). Most parents found alternative explanations for their child's symptoms (Table 1). For example, polydipsia was attributed most commonly to hot weather $(19 / 58,33 \%)$ or infection (13/ $58,22 \%)$, polyuria and nocturia were frequently explained by drinking more $(29 / 47,62 \%$ and $26 / 40,65 \%)$ and tiredness was thought to be school related $(12 / 44,27 \%)$ or secondary to infection $(5 / 44,12 \%)$ or nocturia $(4 / 44,10 \%)$. Worsening or persistent symptoms was the most common reason parents mentioned for seeking medical help $(\mathrm{n}=20)$ and their main concern at presentation was most commonly polydipsia $(n=40)$, followed by polyuria $(n=24)$. Finding alternative explanations for symptoms $(\mathrm{n}=24)$ was the most common reason cited by parents for prolonging the time before diagnosis.

Conclusions The appraisal interval for T1D is complex for parents. Most parents find reasonable alternative explanations for their child's symptoms, which contributes to the time to diagnosis. Future interventions should recognise these difficulties and will need to include more than just a list of symptoms.

\section{G473 OUTCOMES OF ABO INCOMPATIBLE KIDNEY TRANSPLANTATION IN CHILDREN}

1) Stojanovic, ${ }^{2} \mathrm{~N}$ Mamode, ${ }^{2} \mathrm{~A}$ Adamusiak, ${ }^{1} \mathrm{~K}$ Knapp, ${ }^{3} \mathrm{C}$ Barton, ${ }^{3} \mathrm{HE}$ Jones, ${ }^{3} \mathrm{~J}$ Taylor, ${ }^{1}$ SD Marks. 'Department of Paediatric Nephrology, Great Ormond Street Hospital for Children NHS Foundation Trust, London, UK; ${ }^{2}$ Department of Transplantation, Guy's and St Thomas' NHS Foundation Trust, London, UK; ${ }^{3}$ Department of Paediatric Nephrology, Evelina London Children's Hospital, London, UK

\subsection{6/archdischild-2015-308599.427}

Objective $\mathrm{ABO}$ blood group incompatible transplantation (ABOi) has become increasingly common over the last decade, in part due to a shortage of suitable deceased donor allografts. Whilst encouraging data is emerging on short and medium term graft outcomes in adults, ABOi in children is rare; pre-transplant conditioning in paediatric patients remains challenging and concerns persist about an increased risk of rejection. Encouraged by good results in a large number of adult ABOi transplants, we extended our programme to paediatric recipients, and here report the largest European cohort.

Methods A retrospective analysis of all ABOi paediatric renal transplant recipients in the 2 largest centres in the UK sharing the same tailored desensitisation protocol. Patients with pretransplant titres 1 in 8 or above received rituximab one month prior to transplant; tacrolimus and mycophenolate mofetil were started one week pre-op. Antibody removal was performed to 


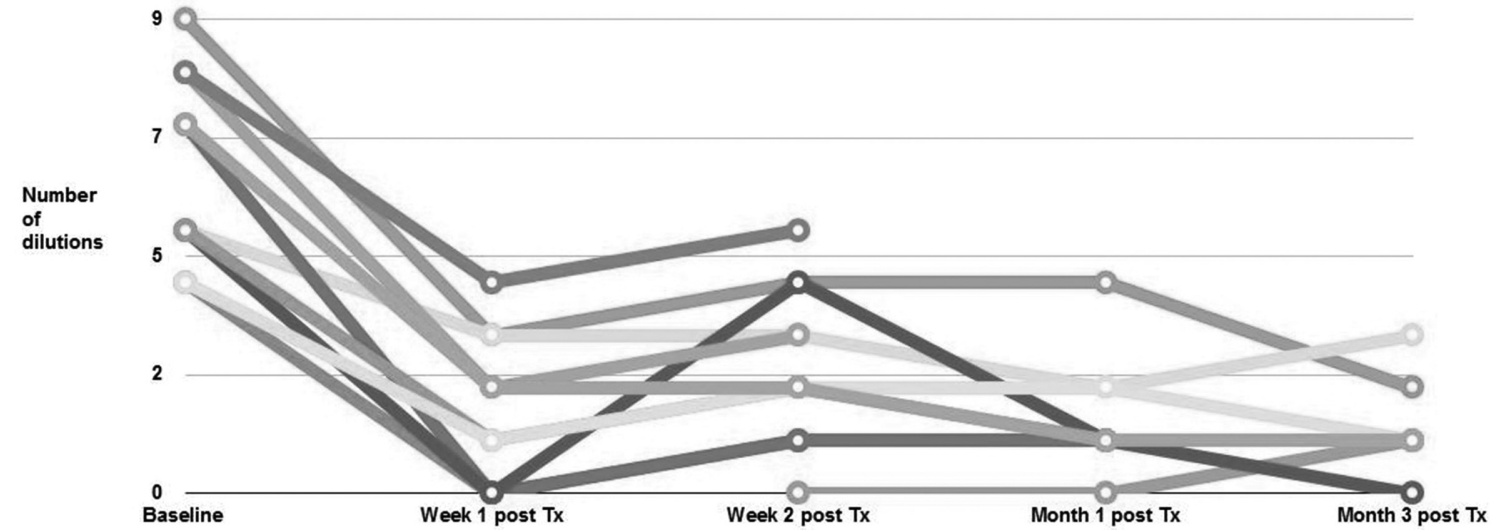

Abstract G473 Figure 1 Blood group titre levels at baseline, week 1 and 2 and month 1 and 3 post transplant

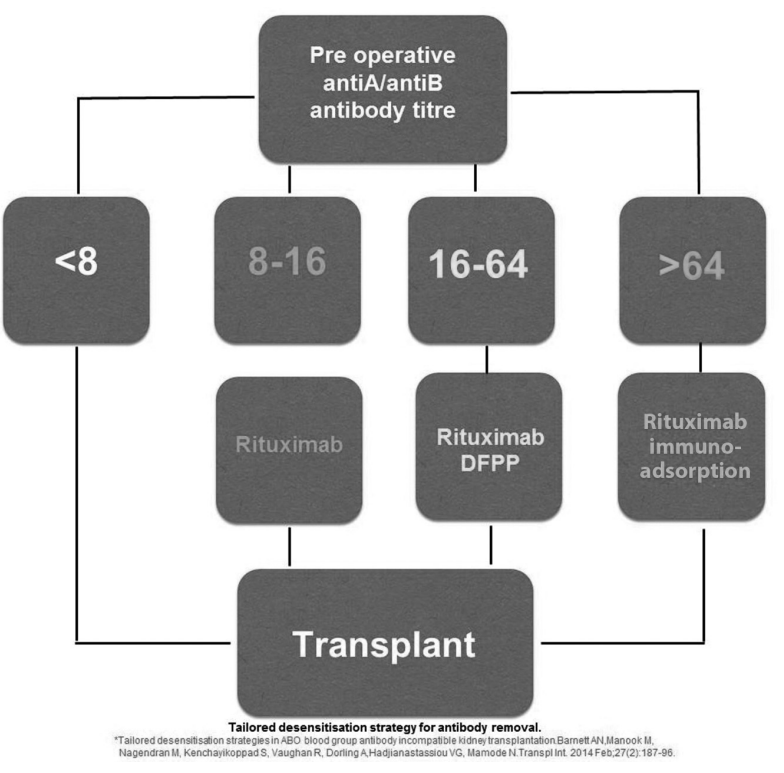

Abstract G473 Figure 2 Tailored desensitisation strategy for antibody removal

reduce titres to 1 in 8 or less at surgery. No routine post-op removal was performed.

Results Ten children (age 2-14 years) underwent an ABOi kidney transplant (Figures 1 and 2 and Table 1). Graft and patient survival was $100 \%$. Baseline titres, tailored desensitisation and graft outcomes are shown in table. One patient developed grade IIa rejection after 2 weeks successfully treated with anti-thymocyte globulin;no histological evidence of rejection in other 9 patients. Another patient had a rise in titre of 2 dilutions at week one treated with 2 immunoadsorption sessions. Nine patients had good graft function (eGFR 30-130 mls/min/ $1.73 \mathrm{~m} 2$ ) at last follow up (range 1-36 months); one patient had eGFR $22 \mathrm{ml} / \mathrm{min} / 1.73 \mathrm{~m} 2$. One patient developed CMV and BK; another EBV and BK.

Conclusion ABOi transplantation in children appears to have an optimal outcome with good graft survival, low risk of rejection and infectious complications.

\section{G474 VARIATION IN PATIENT EXPERIENCE ACROSS PAEDIATRIC DIABETES UNITS (PDUS) IN ENGLAND AND WALES AND ASSOCIATION WITH GLYCAEMIC OUTCOMES}

${ }^{1} \mathrm{D}$ Charalampopoulos, ${ }^{1} \mathrm{R}$ Amin, ${ }^{1} \mathrm{R}$ Viner, ${ }^{2} \mathrm{~J}$ Warner, ${ }^{3} \mathrm{~J}$ Edge, ${ }^{4} \mathrm{~F}$ Campbell, ${ }^{1} \mathrm{~T}$ Stephenson. ${ }^{1}$ Institute of Child Health, University College London, London, UK; ${ }^{2}$ Department of Paediatric Endocrinology, University Hospital of Wales, Cardiff, UK; ${ }^{3}$ Department of Paediatric Endocrinology and Diabetes, Oxford Children's Hospital, Oxford, UK; ${ }^{4}$ Leeds Children's Hospital, Leeds Teaching Hospitals NHS Trust, Leeds, UK

\subsection{6/archdischild-2015-308599.428}

\section{Background/Aims}

Patient Reported Experience Measures (PREMs) are increasingly recognised as an important indicator of healthcare quality. We investigated variation in patient experience across Paediatric Diabetes Units (PDUs) in England and Wales and explored links between PREMs and glycaemic outcomes.

Methods An aggregate analysis of linked PREM and glycaemic data for each PDU collected as part of the 2012-2013 National Paediatric Diabetes Audit (NPDA) was conducted. The percentage of patients/carers who reported a high level of satisfaction (scores 9 or 10/10) in the friends and family recommendation test was used as a quality indicator of diabetes care. A funnel plot of the above indicator was constructed and the 95\% and 99.8\% control limits around the mean were used to distinguish between common-cause (units lying within the control limits) and special-cause variation (units lying outside the control limits). A linear regression model was also fitted for the relationship between mean satisfaction score and mean $\mathrm{HbA}_{1 \mathrm{c}}$ at PDU level.

Results Percentage of patients who reported high satisfaction showed a 2.9 -fold variation (range $35 \%$ to $100 \%$ ) across PDUs with 60/170 (35.3\%) and 33/170 (19.4\%) units falling outside the $95 \%$ and the $99.8 \%$ control limits respectively. Of the 170 PDUs, 21 (12.4\%) lay below the lower 99.8\% control limit (Figure 1). Linear regression showed a significant negative association between mean $\mathrm{HbA}_{1 \mathrm{c}}(\mathrm{mmol} / \mathrm{mol})$ and average satisfaction score for each PDU (regression coefficient $=-2.9$, 95\% CI: -4.7 to $-1.1, \mathrm{p}=0.002$ ) (Figure 2).

Conclusion Patient satisfaction varied considerably across PDUs with one in three units exhibiting more variation than expected by chance. At aggregate level, clinics with higher mean 